\title{
Resenha
}

\section{O adolescente e seus dilemas: orientação para pais e educadores ${ }^{1}$}

\author{
Adolescent and their dilemmas: \\ guidance for parents and educators
}

\author{
Andréia Cristina dos Santos KLEINHANS
}

O livro"O adolescente e seus dilemas: orientação para pais e educadores", organizado por Marilda Emmanuel Novaes Lipp, conta com a participação de vários especialistas que trabalham com adolescentes.

A publicação é aberta com o prefácio de Lipp, que traduz em uma linguagem clara pontos que têm gerado conflito na atualidade. Por exemplo, qual o limiar aceitável entre as práticas educacionais? Os professores têm responsabilidade sobre a educação dos jovens? A autora enfatiza também o fato de não existir um método infalível ou verdades absolutas no que tange à educação dos filhos. Todos os temas abordados servem como disparadores contribuintes na prática educacional dos adolescentes.

Os quinze capítulos deste livro objetivam favorecer reflexões de importantes assuntos sobre a adolescência e seus dilemas. Questões relacionadas à educação, práticas parentais adequadas e temas atuais são abordados por experientes profissionais com o intuito de auxiliar os pais, os professores, os profissionais da área de saúde e os próprios jovens, para os quais a obra foi dedicada exemplarmente.
No primeiro capítulo, Lipp explica os conceitos educação afetiva e estilo parental autoritativo. O primeiro refere-se à valorização das características positivas e ao desenvolvimento de estratégias por parte dos jovens no momento de enfrentar situações conflitantes da vida. Já o segundo, o estilo autoritativo, que é um conjunto de práticas parentais adequadas, propicia a socialização dos jovens. Tal estilo permite a liberdade, mas também coloca limites quando necessário, o que favorece a correta educação.

Com base na ampla experiência clínica e de pesquisa da autora, três temas ainda são abordados: (a) filho adolescente, (b) filho único e (c) filho adulto que mora com os pais. Para cada subitem, Lipp elabora, de forma didática, sugestões que permeiam a educação afetiva e a prática autoritativa salientadas no início do capítulo. Lipp e os demais autores fornecem ao final de cada capítulo as referências bibliográficas, o que favorece a complementação dos assuntos levantados.

No segundo capítulo, Reinhold aborda a educação com sentido estruturado no modelo tridimensional da logoterapia de Viktor Frankl. Para o entendimento do leitor, a autora sintetiza as três dimensões do

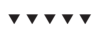

1 Lipp, M. E. N. (Org.). (2011). O adolescente e seus dilemas: orientação para pais e educadores. Campinas: Papirus.

2 Mestranda, Pontifícia Universidade Católica de Campinas, Centro de Ciências da Vida, Programa de Pós-Graduação em Psicologia. Av. Jonh Boyd Dunlop, s/n., Prédio Administrativo, Jd. Ipaussurama, 13090-950, Campinas, SP, Brasil. E-mail: <andreiakleinhans@hotmail.com>. 
modelo de Frankl, a saber, (1) a dimensão somática, que engloba as funções biológicas e fisiológicas, (2) a função psíquica e (3) a dimensão noética ou espiritual. Segundo Reinhold, uma educação com sentido necessita considerar a dimensão noética.

A autora explicita as características principais dos adolescentes que compõem a Síndrome Normal da Adolescência, e também enumera os sete pontos principais que formam a educação com sentido: (1) o sentido como centro constitutivo da educação; (2) os relacionamentos positivos com pessoas envolvidas no processo educativo; (3) a tomada de decisão, solução e ação; (4) o desenvolvimento de competências; (5) a arte como meio de expressão; (6) a curiosidade, o encantamento, a criatividade, a alegria e a esperança; (7) a participação em projetos.

Os capítulos três e quatro complementam os pontos trabalhados por Reinhold. No capítulo três, Witter trabalha as variáveis envolvidas na realização acadêmica, as dificuldades de adaptação das escolas às mudanças atuais, o importante papel da família para o bom desempenho acadêmico e o desenvolvimento do potencial do adolescente. No capítulo quatro, por sua vez, as autoras Scarpatto e Lacerda fornecem importantes dicas para que os pais, os familiares e a escola possam identificar a depressão, as dificuldades escolares e as tendências suicidas dos adolescentes.

Na sequência, os capítulos cinco, seis e sete, escritos respectivamente por Socci, Bignotto e Sadir, tratam de assuntos relativos à sexualidade, ao bullying e suas consequências e às dificuldades de relacionamento que os jovens enfrentam.

No oitavo capítulo, Malagris e Alfano situam os adolescentes na era digital. Eles salientam dicas para os pais e professores sobre o uso consciente dos recursos tecnológicos. As autoras também explicam o cyberbullying e listam instituições que trabalham com o adolescente e a família o vício na internet ou as agressões via internet e sites de relacionamento.

Noções de stress na adolescência, sintomatologia, fontes estressoras e ações preventivas que podem ser usadas com o adolescente quando ele se encontra estressado são explicitadas por Tricoli no nono capítulo.

No décimo capítulo, Lipp orienta os pais e comunidades sobre o uso das drogas na adolescência. A autora enumera diversas dúvidas de pais sobre as ações a serem tomadas em relação ao jovem e apresenta soluções que podem auxiliar a família e o próprio adolescente na resolução do problema.

Outros temas relevantes são abordados nos quatro capítulos seguintes. No capítulo 11, Proença e Cipriano falam a respeito do jovem com comportamento autolesivo. Em seguida, Brasio conceitua e explica as características de distúrbios alimentares, como a anorexia e a bulimia. Já no capítulo 13, Justo traz informações que esclarecem a maneira como o adolescente se comporta diante do desafio da escolha profissional. $O$ trabalho e a convivência familiar são discutidos por Lipp no décimo-quarto capítulo. A autora, inclusive, fornece dicas de uma convivência familiar saudável.

Enfim, o último capítulo escrito por Bignotto se refere à obesidade e ao sedentarismo na adolescência. A autora enumera um programa de tratamento direcionado aos profissionais que trabalham com o jovem que apresenta esse problema.

O livro"O adolescente e seus dilemas: orientação para pais educadores" foi escrito para pessoas que convivem com adolescentes, para que elas possam refletir sobre o assunto. Por abordar temas atuais e relevantes, a obra contempla amplamente as propostas levantadas. O texto apresenta-se, portanto, como uma importante ferramenta de orientação e um guia didático imprescindível para os dias atuais. 